\title{
Microwave-Assisted Extraction of Bound Phenolic Acids in Bran and Flour Fractions from Sorghum and Maize Cultivars Varying in Hardness
}

Constance Chiremba $^{\dagger, \downarrow, \S}$, Lloyd W. Rooney ${ }^{\#}$, Trust Beta ${ }^{\dagger, \zeta, *}$

${ }^{\dagger}$ Department of Food Science, University of Manitoba, Winnipeg, MB, Canada R3T 2N2

${ }^{\ddagger}$ Department of Food Science, University of Pretoria, Private Bag X20,

Hatfield 0028, South Africa

${ }^{\S}$ Agricultural Research Council-Grain Crops Institute, P Bag X1251, Potchefstroom, 2520, South Africa

\#Cereal Quality Laboratory, Department of Soil and Crop Sciences, Texas A\&M University,

College Station, Texas 77843-2474, USA

${ }^{\zeta}$ Richardson Centre for Functional Foods and Nutraceuticals, Smartpark, University of Manitoba, Winnipeg, Manitoba, Canada R3T 2N2

\section{Corresponding author}

*Tel.: +1 204474 8214; Fax: +1 204474 7630. E-mail: Trust_Beta@umanitoba.ca. 
ABSTRACT: To release bound phenolic acids, a microwave-assisted extraction procedure was applied to bran and flour fractions obtained from eight sorghum and eight maize cultivars varying in hardness. The procedure was followed by HPLC analysis and the identities of phenolic acids were confirmed by MS/MS spectra. The extraction of sorghum and maize bound phenolic acids was done for $90 \mathrm{sec}$ in $2 \mathrm{M} \mathrm{NaOH}$ to release ferulic acid and $p$ coumaric acid from bran and flour. Two diferulic acids 8-O-4' and 8-5'-benzofuran form were identified and quantitated in sorghum bran and only the former in maize bran. The contents of ferulic acid and diferulic acids in sorghum bran were 416 to $827 \mu \mathrm{g} / \mathrm{g}$ and 25 to $179 \mu \mathrm{g} / \mathrm{g}$, respectively compared to 2193 to $4779 \mu \mathrm{g} / \mathrm{g}$ and 271 to $819 \mu \mathrm{g} / \mathrm{g}$ in maize. Phenolic acid levels of sorghum were similar between hard and soft cultivars while those of maize differed significantly $(\mathrm{p}<0.05)$ except for ferulic acid in flour. Sorghum phenolic acids were not correlated with grain hardness as measured using a tangential abrasive decortication device. Maize ferulic acid $(\mathrm{r}=-0.601, \mathrm{p}<0.01)$, $p$-coumaric acid $(\mathrm{r}=-0.668, \mathrm{p}<0.01)$ and $8-O$ 4'diferulic acid $(r=-0.629, \mathrm{p}<0.01)$ were significantly correlated with hardness.

KEYWORDS: microwave-assisted extraction, phenolic acids, diferulic acids, sorghum, maize, kernel hardness
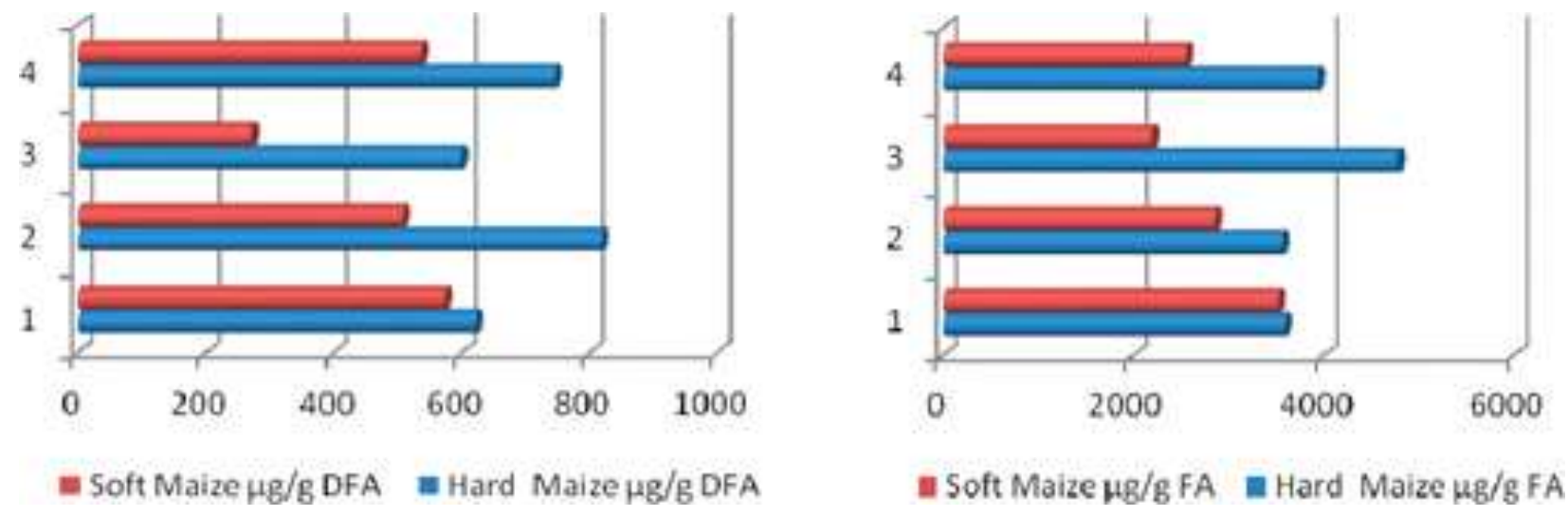


\section{INTRODUCTION}

Besides being energy sources, maize and sorghum are increasingly being recognised as sources of phenolic acids with potential health-promoting antioxidant activity. These phenolic compounds are found in both free and bound forms. However, only a small portion of the phenolic acids is in the free form and the majority are bound to cell walls ${ }^{1}$. In mature plant cell walls, hydroxycinnamic acids, particularly ferulates, are thought to undergo etherification with the earlier esterified phenolic acids ${ }^{2}$, hence forming ester- ether bridges between lignin and polysaccharides. Esterified ferulic acid forms ether linkages with lignin quinone methide intermediates in lignified cell walls. This cross linking is likely to reinforce cell walls and affect grain mechanical properties such as hardness. Grain hardness is the most important parameter for sorghum and maize dry milling quality ${ }^{3}$. However, studies have not fully established the role of bound phenolic acids on sorghum and maize grain hardness. Hence, there is need to effectively extract the bound phenolic acids and relate them to grain hardness.

Microwave-assisted extraction (MAE) offers an alternative to the traditional, protracted alkaline refluxing used for releasing ester and ether-bound phenolic acids. The advantages of MAE include rapidity, reduced solvent consumption and high phenolic yield ${ }^{4}$. Furthermore, the technique combines high temperature and high pressure for optimal release of phenolic acids with the concomitant breakdown of the cell walls. This procedure used previously to release etherified ferulic acid acid in several plant tissues including cereal straws ${ }^{5}$, flaxseed ${ }^{4}$ and herbs ${ }^{6}$ resulted in higher quantities of ferulic acid than traditional alkaline hydrolysis. Rose and Inglett ${ }^{7}$ applied microwave irradiation to hydrolyze maize bran samples with the aim of releasing feruloylated arabinoxyl-oligosaccharides in which water was used for MAE followed by alkaline hydrolysis. In this study, sorghum and maize cereal 
grains were hydrolyzed using MAE with the objective of maximizing the release of bound phenolic acids and studying their relationship to grain hardness.

\section{MATERIALS AND METHODS}

\section{Materials.}

A study was conducted on eight sorghum and eight maize cultivars grown in South Africa representing commercial hybrids varying in grain hardness, from the National Cultivar Trials harvested during the 2008/2009 growing season. Maize cultivars were white dent types grown in Potchefstroom. Sorghum cultivars were red, non-tannin grown in Platrand. All cultivars were grown in dryland conditions, harvested at less than $14 \%$ moisture and dried slowly. Their physical and hardness properties are shown in Tables 1 and 2. Phenolic acid standards were purchased from Sigma-Aldrich Chemical Co. (St. Louis, MO, USA). HPLC grade hexane, ethyl acetate and methanol were used for phenolic acids extraction. MS grade methanol and acetic acid were used in LC-MS/MS. The solvents were also purchased from Sigma-Aldrich Chemical Co. (St. Louis, MO, USA). For phenolic assays, bran and flour portions were separated by decorticating grain to $80 \%$ extraction rate with a Tangential Abrasive Dehulling Device (TADD), Model 4E- 115 (Venables Machine Works, Saskatoon, SK, Canada). Separation was achieved by optimizing decortication time for each cultivar to abrade $20 \%$ of the kernel. 
Table 1. Physical and Hardness Characteristics of Sorghum ${ }^{a, b}$

\begin{tabular}{lccccccc}
\hline Cultivar & TW & TKW & $>4.00 \mathrm{~mm}$ & $>3.35<4.00$ & $>3.15<3.35$ & $>2.36<3.15$ & TADD \\
\hline Hard Cultivars & & & & & & & \\
Range & $75.9-77.7$ & $25.0-26.2$ & $0.3-3.6$ & $52.5-65.8$ & $11.8-18.8$ & $9.9-13.2$ & $26.7-37.6$ \\
Mean & $77.0^{\mathrm{a}}(0.7)$ & $25.6^{\mathrm{a}}(0.9)$ & $1.3^{\mathrm{a}}(1.46)$ & $60.9^{\mathrm{a}}(5.6)$ & $16.5^{\mathrm{a}}(3.0)$ & $11.9^{\mathrm{a}}(1.4)$ & $33.3^{\mathrm{a}}(4.9)$ \\
\hline Soft Cultivars & & & & & \\
Range & $75.2-77.7$ & $19.8-28.0$ & $0.1-2.2$ & $19.4-65.8$ & $12.5-31.2$ & $8.8-38.5$ & $37.6-49.2$ \\
Mean & $76.2^{\mathrm{a}}(1.0)$ & $25.0^{\mathrm{a}}(3.5)$ & $1.4^{\mathrm{a}}(0.9)$ & $50.7^{\mathrm{b}}(19.7)$ & $17.9^{\mathrm{a}}(8.3)$ & $17.6^{\mathrm{a}}(13.0)$ & $42.6^{\mathrm{a}}(6.3)$ \\
\hline
\end{tabular}

${ }^{a}$ TW, test weight $(\mathrm{kg} / \mathrm{hl})$; TKW; thousand kernel weight $(\mathrm{g})$; kernels passing through $>2.36 \mathrm{~mm}>4.00 \mathrm{~mm}(\mathrm{~g})$; TADD; \% kernel removed by TADD abrasion.

${ }^{b}$ Figures in parentheses are standard deviations. Different superscript letters in the same column denote significant differences $(\mathrm{p}<0.05)$ between hard and soft cultivars, respectively.

Table 2. Physical and Hardness Characteristics of Maize Cultivars ${ }^{a, b}$

\begin{tabular}{lcccccc}
\hline \multicolumn{1}{c}{ Cultivar } & TW & SB & KS & TKW & TADD & NIT \\
\hline Hard cultivars & & & & & & \\
Range & $79.4-82.0$ & $1.98-2.73$ & $74.5-83.0$ & $397-444$ & $23.4-25.2$ & $91.0-99.6$ \\
Mean & $80.6(1.4)$ & $2.38(0.76)$ & $78.2(6.5)$ & $421(48)$ & $24.1(1.9)$ & $95.8(6.2)$ \\
\hline Soft cultivars & & & & & & \\
Range & $78.6-86.1$ & $1.7-4.11$ & $77.0-83.7$ & $373-422$ & $29.1-31.2$ & $84.1-95.7$ \\
Mean & $81.2(4.7)$ & $3.35(1.13)$ & $80.9(3.5)$ & $403(33)$ & $30.3(2.1)$ & $87.8(6.9)$ \\
\hline
\end{tabular}

${ }^{a} \mathrm{TW}$, test weight $(\mathrm{kg} / \mathrm{hl}) ; \mathrm{SB}, \%$ breakage susceptibility by Steiner breakage tester; TKW; thousand kernel weight (g); TADD; \% kernel removed by TADD abrasion; KS; \% kernel size $\geq 8$ mm; NIT, Near Infrared Transmittance milling index.

${ }^{b}$ Figures in parentheses are standard deviations. Means were not significantly different $(\mathrm{p}<0.05)$.

\section{Microwave-assisted sample extraction.}

A $200 \mathrm{mg}$ portion of the maize or sorghum sample was extracted with $5 \mathrm{~mL}$ of $2 \mathrm{M}$ $\mathrm{NaOH}$ using a $45 \mathrm{~mL}$ PTFE acid digestion bomb vessel (Parr Instrument Company, Moline, IL, USA). The bomb vessel was placed in a $1400 \mathrm{~W}$ domestic microwave oven (Diplomat Model D811, Danby, Suweon, Korea) set at $100 \%$ power to achieve $190{ }^{\circ}$ C. Samples were digested for $45 \mathrm{sec}$. The hydrolysate was adjusted to a $\mathrm{pH}$ of 1.5 to 2.0 using $6 \mathrm{~N} \mathrm{HCl}$ and 
extracted three times with $15 \mathrm{~mL}$ hexane to remove lipids ${ }^{8}$. The organic phase was removed with a separator and the aqueous phenolic phase extracted three times with ethyl acetate to obtain the alkali released phenolics. The organic phase was further dehydrated with $1 \mathrm{~g}$ $\mathrm{Na}_{2} \mathrm{SO}_{4}$. The combined ethyl acetate extracts were dried and concentrated under vacuum using a rotary evaporator. The dried phenolic extracts were redissolved in $2 \mathrm{~mL}$ of $50 \%$ methanol and filtered with a $22 \mu \mathrm{m}$ nylon filter before HPLC and MS/MS analysis for phenolic acids.

\section{Analyses.}

HPLC-MS/MS analysis.

HPLC analysis of phenolic acids was performed on a Waters 2695 HPLC equipped with a Waters 996 photodiode array (PDA) and an auto sampler (717 Plus, Waters) to inject $10 \mu \mathrm{L}$ of sample described by Qiu et al $^{8}$, but with modifications. Instead, a Shimadzu RP analytical column $(250 \times 4.6 \mathrm{~mm}, 5 \mu \mathrm{m})$ was used and phenolic acid separation was achieved using a $70 \mathrm{~min}$ linear solvent gradient at a flow rate of $0.7 \mathrm{~mL} / \mathrm{min}$. The gradient mobile phase solvent $\mathrm{A}$ was $0.1 \%$ acetic acid in high purity water and solvent $\mathrm{B}$ was $0.1 \%$ acetic acid in methanol. The solvent gradient was as follows: 0 min $4 \% \mathrm{~B}, 18 \mathrm{~min} 18 \% \mathrm{~B}, 35 \mathrm{~min}$ $30 \% \mathrm{~B}, 58 \mathrm{~min} 42 \% \mathrm{~B}, 70 \mathrm{~min} 60 \% \mathrm{~B}$, and $10 \mathrm{~min}$ to rinse and equilibrate the column. Phenolic acid quantitation was based on the standard curves of the corresponding phenolic acids at a wavelength of $320 \mathrm{~nm}$ and peak area was used for calculations. Identification of phenolic acids was performed by comparison to the retention time and MS/MS spectra with external standards. MS/MS was conducted using a quadrupole time-of-flight mass spectrometer (Q-TOF MS) (Micromass, Waters Corp., Milford, MA) according to Qiu et al ${ }^{8}$. In this study, full mass spectra were acquired in the negative mode using cone and capillary voltages of $30 \mathrm{~V}$ and $1.6 \mathrm{kV}$, respectively. Desolvation and cone gases $(\mathrm{He})$ were set to flow 
at $900 \mathrm{~L} / \mathrm{h}$ and $35 \mathrm{~L} / \mathrm{h}$, respectively while the desolvation temperature and the source temperatures were $350{ }^{\circ} \mathrm{C}$ and $150{ }^{\circ} \mathrm{C}$, respectively. MS/MS spectra were acquired using collision energy of $25 \mathrm{~V}$ in the range $\mathrm{m} / \mathrm{z} .100-1500$.

Statistical analysis.

All experiments were done in triplicate. Means were compared by Fisher's least significant differences. Pearson's correlation was performed to determine the relationship between parameters. Calculations were performed using Statgraphics Centurion XV (StatPoint, Herndon, Virginia, USA).

\section{RESULTS AND DISCUSSION}

\section{Optimization of microwave-assisted alkaline extraction conditions.}

Samples were microwaved at $15 \mathrm{sec}$ intervals in $2 \mathrm{M} \mathrm{NaOH}$ to optimize extraction. Complete solubilisation was achieved after $45 \mathrm{sec}$ in both sorghum and maize grain samples compared to the conventional alkaline hydrolysis, which takes at least $2 \mathrm{~h}$. In conventional alkaline hydrolysis sample solubilisation was incomplete as shown by visible particles after hydrolysis. The duration of extraction used in this study was shorter than reported previously 5,7. The differences in extraction conditions could be attributed to different microwave units, power settings, extractants and sample type. Microwave oven temperature was set at $190{ }^{\circ} \mathrm{C}$, a temperature deemed sufficient to break the ether bonds which are heat labile at $170{ }^{\circ} \mathrm{C}$

\section{Identification of microwave extracted bound phenolic acids in sorghum.}

Phenolic compounds were identified by comparing their retention times $\left(t_{R}\right)$ and mass spectra with those of external standards. Para-coumaric acid and ferulic acid were the only 
phenolic acids positively identified in both sorghum and maize. Two diferulic acids were identified in sorghum and Figure 1 (A-C) shows peaks obtained at $320 \mathrm{~nm}, 280 \mathrm{~nm}$ and the total ion chromatogram, respectively. There were more compounds detected at $280 \mathrm{~nm}$ than $320 \mathrm{~nm}$ although most of the compounds could not be identified with $t_{R}$ and masses of the external standards. $p$-coumaric acid and ferulic acid were the only monomeric phenolic acids identified at $t_{\mathrm{R}} 38.9 \mathrm{~min}$ and $42.3 \mathrm{~min}$, respectively. The identity of the peaks was confirmed with mass spectrometric data acquired in the negative ionization mode based on the molecular ions $[\mathrm{M}-\mathrm{H}]^{-}$and fragmentation patterns (Figure 2A-D). Figure $3 \mathrm{C}$ and D show the main fragments and mass spectra of ferulic acid and $p$-coumaric acid, respectively. Ferulic acid $(m / z$ 193) produced a fragment at $m / z 178$ due to the loss of a methyl group (15 Da) from the parent ion. Another fragment was generated at $\mathrm{m} / \mathrm{z} 134$ due to the loss of both the methyl group and carbon dioxide. Para coumaric acid $(\mathrm{m} / \mathrm{z}, 163)$ produced fragment ions at $\mathrm{m} / \mathrm{z} 119$ corresponding to the loss of carbon dioxide (44 Da). Hossain et al ${ }^{10}$ reported the loss of carbon dioxide in $p$-coumaric acid and ferulic acid from the parent ions characterised in Lamiaceae spices. Besides ferulic acid and $p$-coumaric acid, three peaks at $\mathrm{t}_{\mathrm{R}} 21.4,26.9$ and $29.8 \mathrm{~min}$ were obtained at both $280 \mathrm{~nm}$ and $320 \mathrm{~nm}$. Their identities were not confirmed with external standards and mass spectrometric data but they were assumed to be derivatives of hydroxycinnamic acids, due to their absorption pattern. The rest of the peaks were only detected at $280 \mathrm{~nm}$, and excluded at $320 \mathrm{~nm}$, typical of hydroxybenzoic acid derivatives.

Two diferulic acids with $\mathrm{m} / \mathrm{z}, 385$, were identified. The diferulic acidswere eluted at $\mathrm{t}_{\mathrm{R}} 66.7$ min and $44.5 \mathrm{~min}$ and their mass spectra corresponded to 8-O-4' (Figure 2A) and 8-5'benzofuran form, (Figure 2B), respectively. The assignments were in agreement with mass spectra data and fragmentation patterns reported in literature ${ }^{8,11,12}$. The deprotonated $8-5^{\prime}-$ benzofuran form diferulic acid $[\mathrm{M}-\mathrm{H}]^{-}$produced a fragment with $m / z, 341$ due to the loss of carbon dioxide (44 Da) from the carboxylic acid group. Both diferulic acids produced a 

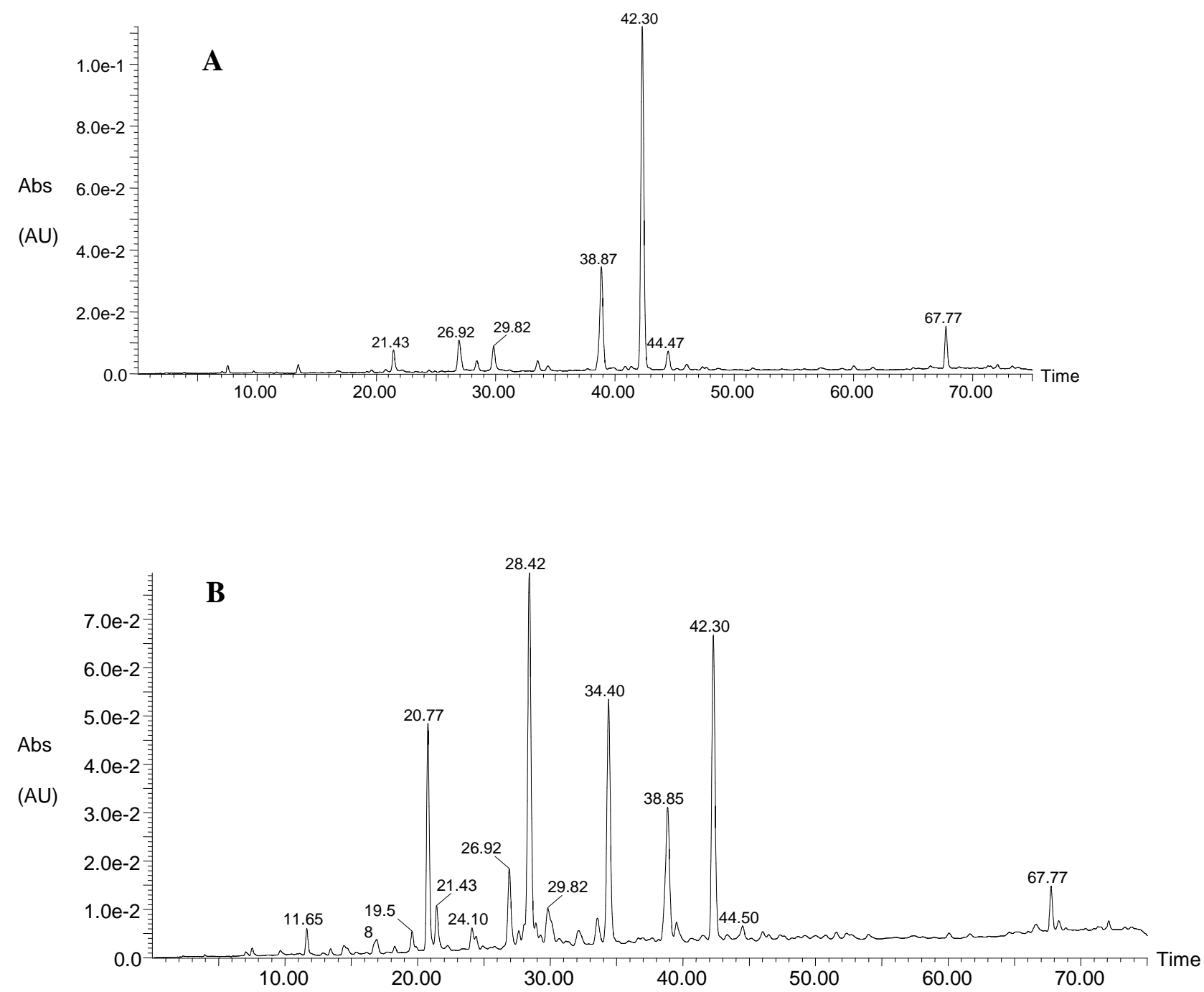


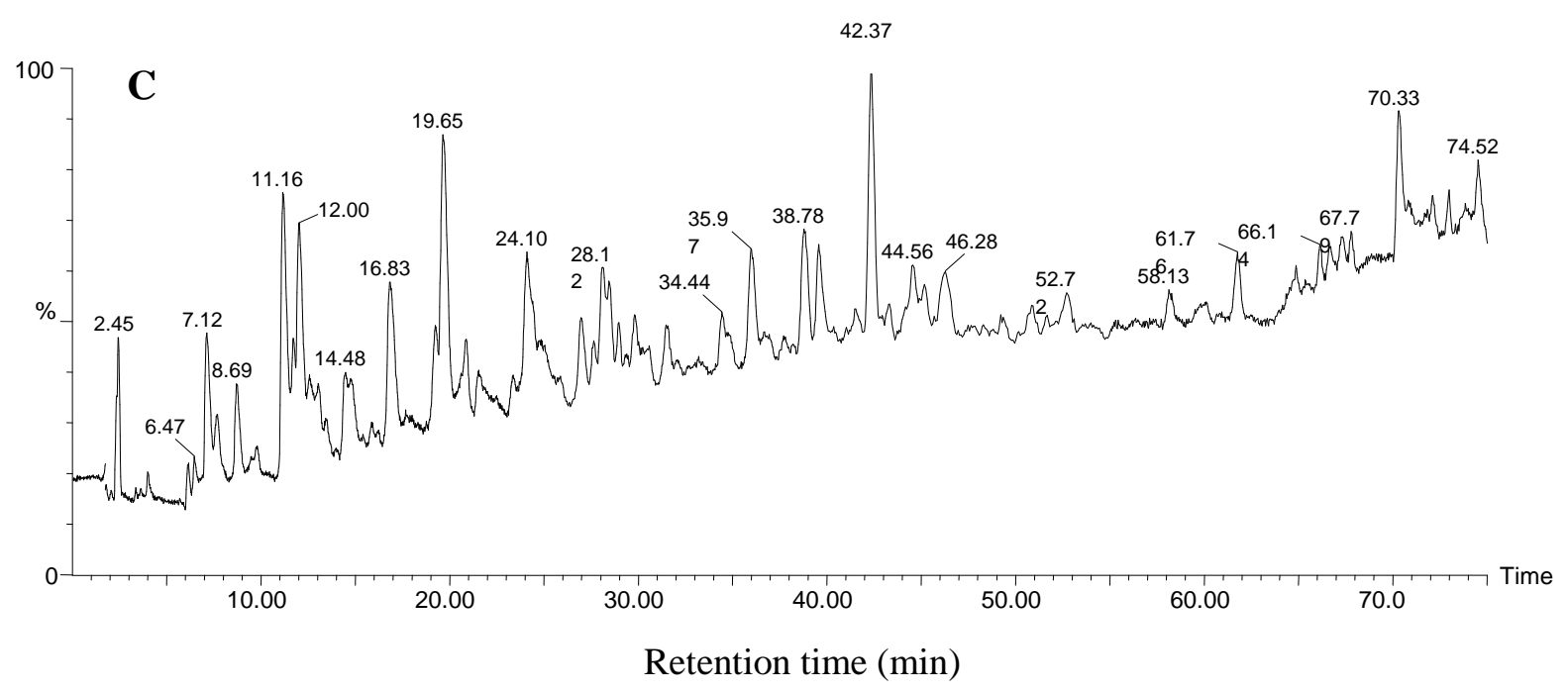

Figure 1. LC chromatogram of phenolic acids in sorghum bran of cultivar PAN 8564 at (A) $320 \mathrm{~nm}$, (B) 280 $\mathrm{nm}$ and $(\mathrm{C})$ the total ion chromatogram.

fragment with $m / z 326$ due to the loss of carbon dioxide and a methyl group (59 Da). The loss of carbon dioxide is typical of phenolic acids with the resultant $[\mathrm{M}-\mathrm{H}-\mathrm{COO}]^{-}$anion ${ }^{10,13}$. The diferulic acids were expected and confirmed earlier reports that 8-O-4' and 8-5'benzofuran form were the most abundant diferulic acid in cereals ${ }^{14,15}$. 

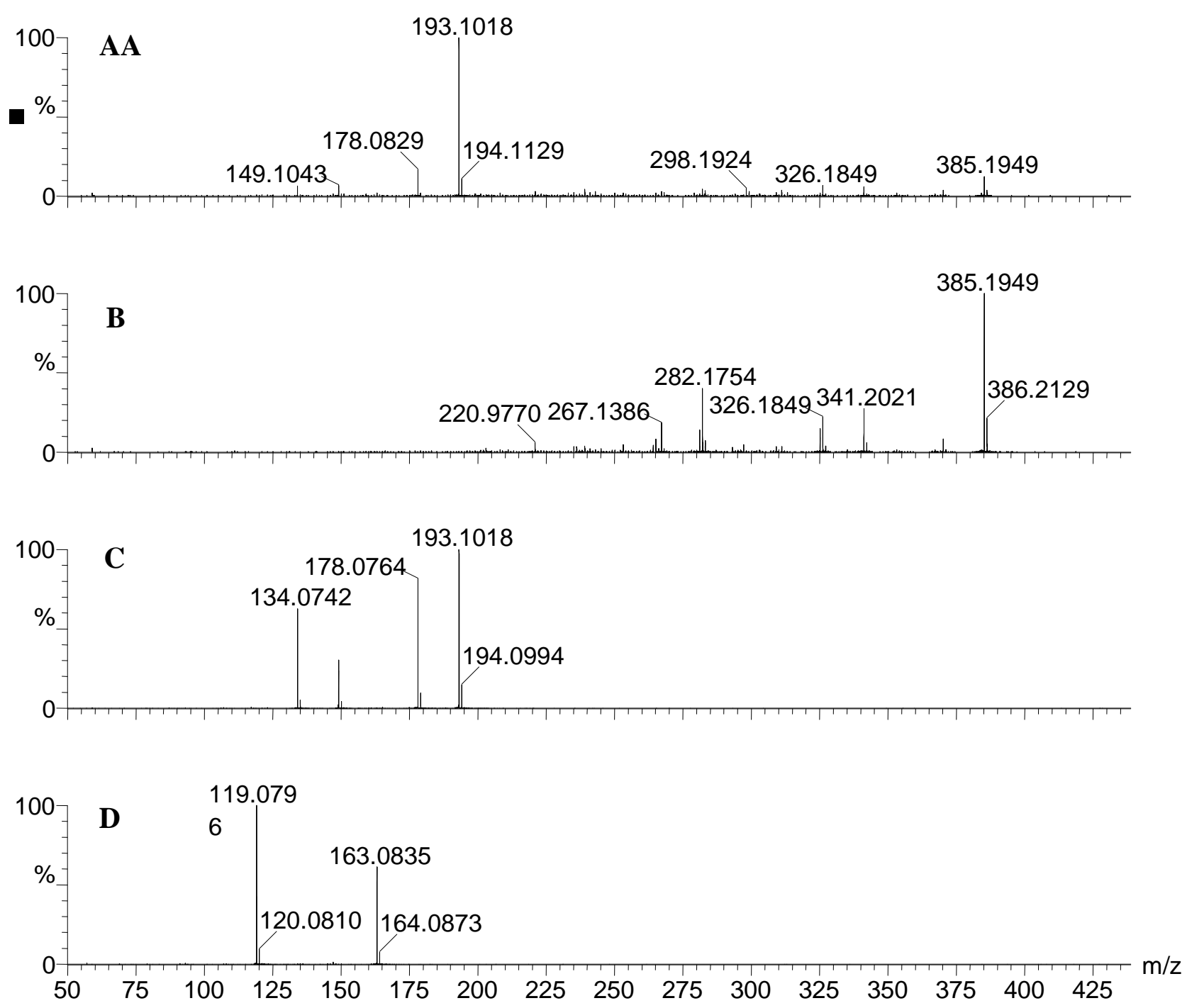

Figure 2. MS/MS spectra of (A) 8-O-4' diferulic acid (66.8 min), (B) 8-5'-benzofuran form diferulic acids (44.5 min), (C) ferulic acid (42.3 min) and (D) p-coumaric acid (38.9 min) of sorghum bran cultivar PAN 8564. 


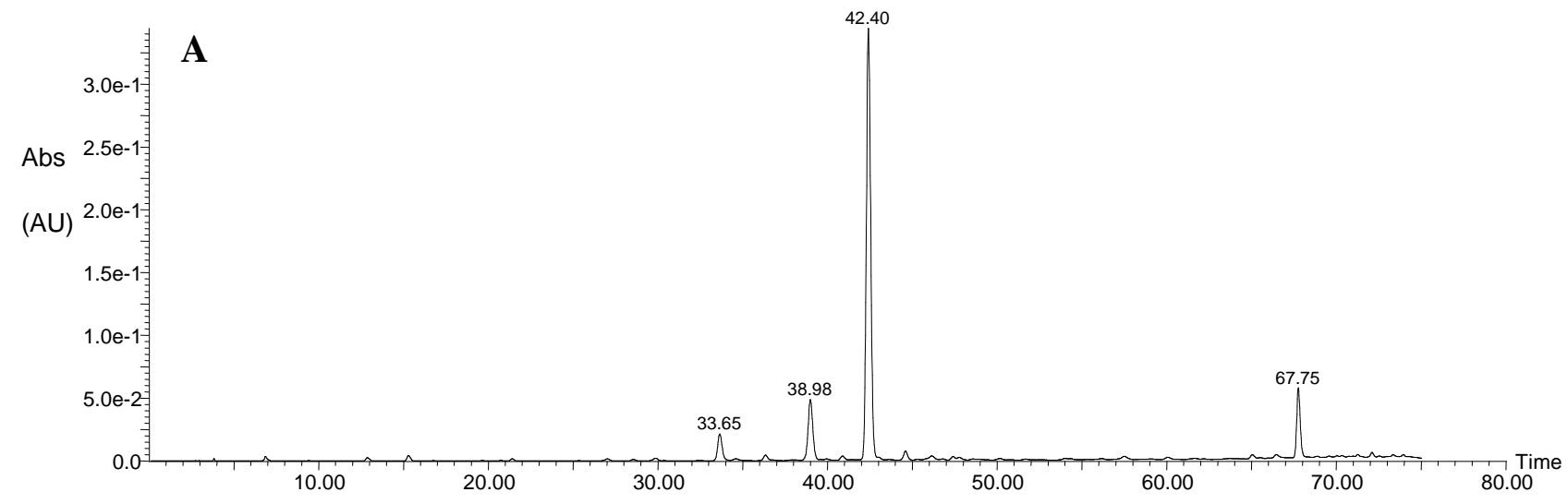

B
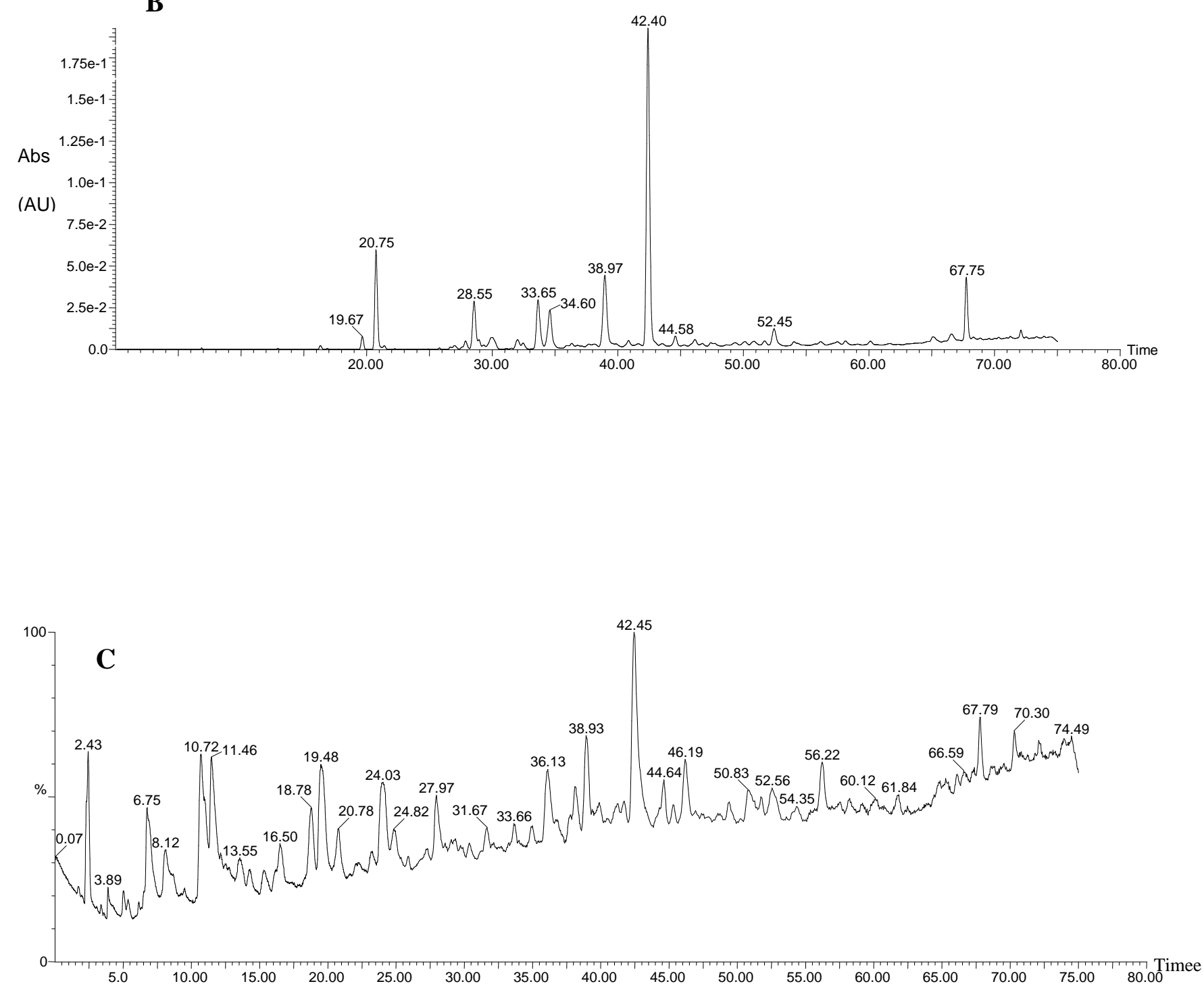

Retention time (min) 
Figure 3. LC chromatogram of phenolic acids in maize bran of cultivar AFG 4555 at (A) $320 \mathrm{~nm}$, (B) $280 \mathrm{~nm}$ and $(\mathrm{C})$ the total ion chromatogram.

Identification of microwave extracted bound phenolic acids in maize. Several peaks were obtained in maize samples as shown (Figure 3A-D). However, only p-coumaric acid and ferulic acid were identified using retention times of external standards. An unknown peak that eluted at $t_{R} 33.7 \mathrm{~min}$ at both $280 \mathrm{~nm}$ and $320 \mathrm{~nm}$ was assumed to be a hydroxycinnamic derivative. Most of the peaks detected at $280 \mathrm{~nm}$ but not detected at $320 \mathrm{~nm}$ would be hydroxybenzoic acid derivatives. The unconfirmed peaks eluted at $t_{R} 19.67,20.8$, 28.6 and 34.6 min (Figure 3B) were also observed in sorghum.

MS/MS data was used to confirm the identities of the phenolic acids. The fragmentation pattern of $p$-coumaric acid and ferulic acid followed that of sorghum as described above. The identity of the other compounds could not be confirmed using their MS/MS spectra. One diferulic acid was obtained at $t_{R} 67.8$, similar to that identified in sorghum although two diferulic acids were detected in the latter. The diferulic acid was assigned $8-O-4^{\prime}$ due to its fragmentation pattern. $8-O-4^{\prime}$ diferulic acid is among one of the commonly found diferulic acids in cereal grains ${ }^{14}$.

\section{Quantitation of microwave extracted bound phenolic acids of sorghum bran and flour fractions.}

The quantities of sorghum bran and flour phenolic acids are shown in Table 3. Within the hard cultivars, bran of PAN 8488 had the lowest $p$-coumaric acid and ferulic acid contents while PAN 8902 had the highest ferulic acid and diferulic acids contents. Within the bran of soft cultivars, $p$-coumaric acid occurred over a wider range (38 to $222 \mu \mathrm{g} / \mathrm{g}$ ) than hard cultivars (85 to $228 \mu \mathrm{g} / \mathrm{g}$ ). The significant differences in bran $p$-coumaric acid $(\mathrm{p}<0.05$ ) of 
soft cultivars could be useful to distinguish among hard and soft grain samples. Bran of PAN 8903 had the lowest phenolic acid content particularly $p$-coumaric acid and diferulic acids which were up to six and seven times less than other cultivars, respectively. Overall, there were no significant differences $(\mathrm{p}>0.05)$ in bran phenolic acid content between the hard and soft cultivars following MAE.

Table 3. Bound Phenolic Acids of Sorghum Bran and Flour Fractions Released by Microwave Assisted Alkaline Extraction $(\mu \mathrm{g} / \mathrm{g})^{a}$

\begin{tabular}{llllll}
\hline Cultivar & Bran & & & Flour & \\
& PCA & FA & DFA & PCA & FA \\
\hline Hard cultivars & & & & \\
PAN 8902 & $108 \mathrm{bcB}(8)$ & $827 \mathrm{aA}(10)$ & $179 \mathrm{aA}(4)$ & $24.5 \mathrm{dC}(1.8)$ & $98 \mathrm{abB}(4)$ \\
PAN 8905 & $228 \mathrm{aA}(11)$ & $445 \mathrm{dC}(18)$ & $108 \mathrm{cC}(4)$ & $32.2 \mathrm{cB}(1.8)$ & $110 \mathrm{aA}(2)$ \\
PAN 8564 & $106 \mathrm{bcB}(5)$ & $643 \mathrm{bcB}(14)$ & $131 \mathrm{bB}(6)$ & $40.1 \mathrm{bA}(1.5)$ & $37 \mathrm{eC}(2)$ \\
PAN 8488 & $85 \mathrm{dC}(5)$ & $416 \mathrm{dC}(6)$ & $112 \mathrm{cC}(6)$ & $41.6 \mathrm{abA}(3.1)$ & $111 \mathrm{aA}(8)$ \\
Mean & $132^{\mathrm{a}}(60)$ & $583^{\mathrm{a}}(178)$ & $133^{\mathrm{a}}(30)$ & $34.6^{\mathrm{a}}(7.5)$ & $89^{\mathrm{a}}(33)$ \\
\hline Soft cultivars & & & & & \\
PAN 8901 & $222 \mathrm{aA}(10)$ & $680 \mathrm{bA}(8)$ & $170 \mathrm{aA}(9)$ & $16.7 \mathrm{fC}(1.8)$ & $108 \mathrm{aA}(4)$ \\
PAN 8903 & $38 \mathrm{eD}(3)$ & $445 \mathrm{dC}(7)$ & $25 \mathrm{dC}(1)$ & $22.5 \mathrm{eB}(2.0)$ & $65 \mathrm{dC}(3)$ \\
PAN 8906 & $90 \mathrm{cC}(3)$ & $619 \mathrm{cB}(6)$ & $110 \mathrm{cB}(2)$ & $14.8 \mathrm{fC}(0.9)$ & $84 \mathrm{bcB}(3)$ \\
PAN 8904 & $122 \mathrm{bB}(5)$ & $613 \mathrm{cB}(12)$ & $172 \mathrm{aA}(5)$ & $48.1 \mathrm{aA}(0.7)$ & $78 \mathrm{cdB}(1)$ \\
\hline Mean & $118^{\mathrm{a}}(72)$ & $589^{\mathrm{a}}(94)$ & $119^{\mathrm{a}}(64)$ & $25.6^{\mathrm{a}}(14.3)$ & $84^{\mathrm{a}}(17)$ \\
\hline
\end{tabular}

\footnotetext{
${ }^{a}$ Figures in parentheses are standard deviations. Different lower case, uppercase and superscript letters in the same column denote significant differences $(\mathrm{p}<0.05)$ among all cultivars, within the hard and soft and between hard and soft cultivars, respectively. PCA, $p$-coumaric acid; FA, ferulic acid; DFA, diferulic acid.
}

Para coumaric acid and ferulic acid were identified and quantitated in the sorghum flours. Within the hard cultivars, ferulic acid content of PAN 8564 and was up to three times less than the other cultivars. Overall, $p$-coumaric acid and ferulic acid of flours were not significantly different $(\mathrm{p}>0.05)$ between hard and soft cultivars. Since most phenolic acids 
are concentrated in the bran, significant variations in their levels were not expected in the endosperm, the major component of the flours. Diferulic acids content was also not significantly different $(\mathrm{p}>0.05)$ between the hard and sot sorghum cultivars. PAN 8903 was an exception as it contained almost seven times less diferulic acids than both hard and soft cultivars. PAN 8903 was also characterised by lower values of $p$-coumaric acid and ferulic acid within the soft sorghum cultivars. With the exception of PAN 8903, the diferulic acids content of the sorghum cultivars was between four and six times less than ferulic acid content due to the lack of lignified cell walls in the endosperm.

\section{Quantitation of microwave extracted bound phenolic acids of maize bran and flour}

\section{fractions.}

The contents of bran phenolic acids varied among the maize cultivars. There were significant differences $(\mathrm{p}<0.05)$ in bran phenolic acid content between hard and soft samples (Table 4). Ferulic acid was the predominant phenolic acid in the bran as previously reported ${ }^{14}$, followed by $p$-coumaric acid. On average, there was a larger variation in FA (range 1189 $\mu \mathrm{g} / \mathrm{g}$ ) than $p$-coumaric acid (range $179 \mu \mathrm{g} / \mathrm{g}$ ) between hard and soft cultivars. AFG 4555 had the highest amount of ferulic acid $(4779 \mu \mathrm{g} / \mathrm{g})$ with at least $25 \%$ more ferulic acid than the other hard cultivars. PAN 6223 B had up to $38 \%$ more ferulic acid than bran from other soft cultivars. Diferulic acids were significantly different $(\mathrm{p}<0.05)$ between the hard and soft cultivars. Although AFG 4555 had the highest ferulic acid, its diferulic acids content was the lowest within the hard maize cultivars. This trend was not observed for soft cultivars as high ferulic acid content corresponded with high diferulic acids content and vice versa. 
Table 4. Bound Phenolic Acids of Maize Bran and Flour Fractions Released by Microwave Assisted Alkaline Extraction $(\mu \mathrm{g} / \mathrm{g})^{a}$

\begin{tabular}{llllll}
\hline Cultivar & \multicolumn{3}{c}{ Bran } & & Flour \\
& PCA & FA & DFA & PCA & FA \\
\hline Hard cultivars & & & & & \\
IMP 52 - 11 & $255 \mathrm{deD}(21)$ & $3592 \mathrm{cC}(119)$ & $622 \mathrm{cC}(12)$ & $151 \mathrm{aA}(5)$ & $345 \mathrm{bB}(10)$ \\
DKC 77 - 61 B & $345 \mathrm{cC}(38)$ & $3564 \mathrm{cC}(112)$ & $819 \mathrm{aA}(2)$ & $159 \mathrm{aA}(7)$ & $260 \mathrm{cdC}(8)$ \\
AFG 4555 & $547 \mathrm{aA}(15)$ & $4779 \mathrm{aA}(220)$ & $599 \mathrm{cdC}(12)$ & $37 \mathrm{bB}(2)$ & $470 \mathrm{aA}(13)$ \\
LS 8521 B & $463 \mathrm{bB}(31)$ & $3944 \mathrm{bB}(163)$ & $746 \mathrm{bB}(25)$ & $25 \mathrm{cC}(2)$ & $287 \mathrm{cC}(11)$ \\
Mean & $403^{\mathrm{a}}(121)$ & $3970^{\mathrm{a}}(538)$ & $696^{\mathrm{a}}(97)$ & $93^{\mathrm{a}}(66)$ & $341^{\mathrm{a}}(87)$ \\
\hline Soft cultivars & & & & & \\
PAN 6223 B & $319 \mathrm{cdA}(15)$ & $3517 \mathrm{cA}(100)$ & $573 \mathrm{dA}(37)$ & $24 \mathrm{cA}(1)$ & $235 \mathrm{dC}(8)$ \\
PAN 4P - 313 B & $185 \mathrm{efC}(8)$ & $2862 \mathrm{~dB}(65)$ & $507 \mathrm{eB}(35)$ & $25 \mathrm{cA}(2)$ & $281 \mathrm{cB}(16)$ \\
AFG 4473 & $221 \mathrm{efB}(15)$ & $2193 \mathrm{fD}(39)$ & $271 \mathrm{fC}(15)$ & $24 \mathrm{cA}(2)$ & $435 \mathrm{aA}(13)$ \\
AFG 4517 & $171 \mathrm{fC}(11)$ & $2551 \mathrm{eC}(17)$ & $536 \mathrm{deAB}(23)$ & $23 \mathrm{cA}(2)$ & $273 \mathrm{cB}(12)$ \\
\hline Mean & $224^{\mathrm{b}}(63)$ & $2781^{\mathrm{b}}(522)$ & $472^{\mathrm{b}}(130)$ & $306^{\mathrm{a}}(82)$ \\
\hline
\end{tabular}

\footnotetext{
${ }^{a}$ Figures in parentheses are standard deviations. Different lower case, uppercase and superscript letters in the same column denote significant differences $(\mathrm{p}<0.05)$ among all cultivars, within the hard and soft and between hard and soft cultivars, respectively. PCA, $p$-coumaric acid; FA, ferulic acid; DFA, diferulic acid.
}

Similarly, ferulic acid and $p$-coumaric acid were the only phenolic acids identified and quantitated in maize flours $p$-coumaric acid was almost four times higher in hard cultivars than soft cultivars. However, within the hard cultivars there was a large variation in $p$-coumaric acid (25 to $159 \mu \mathrm{g} / \mathrm{g}$ ). There were no significant differences ( $\mathrm{p}>0.05$ ) in the $p$ coumaric acid of soft cultivar flours. Ferulic acid was similar between hard and soft cultivars although cultivars AFG 4555 and AFG 4473 had exceptionally high ferulic acid content in the hard and soft groups, respectively. 
The high temperature used for extraction likely degraded some monomeric phenolic acids. However, the stable ferulic acid and p-coumaric acid were retained. In contrast, high temperature was expected to breakdown ether bonds in cells walls and increase the release and diffusion of oligomeric phenolic acids into the alkali. However, only two diferulic acids were identified in sorghum and one in maize. The diferulic acids released by MAE were also less than the quantities reported for maize dietary fibre ${ }^{16}$ probably owing to sample composition and preparation before extraction. The latter extracted the diferulic acids from isolated cell walls. Although the microwave conditions were set such that the temperature was sufficient to cause ether bond breakage, generally sorghum diferulic acids content was low. Moreover total solubilisation of the sample was expected to increase phenolic acid release by means of cell wall breakage. There were large differences between the sorghum and maize phenolic acid contents despite the two cereal grains being similar in structure, chemical composition and basis for grain hardness ${ }^{17}$. The differences in the diferulic acids content and composition of sorghum and maize cultivars could be due to variations in their biosynthesis and cross-linking hence affecting the degree of alkaline hydrolysis and breakage of ether bonds ${ }^{18}$. The time for extraction could have been insufficient to break all the sorghum ether bonds and release the diferulic acids despite the likelihood that the temperature generated would enhance mass transfer by increasing solid solubility and diffusion of solubilised phenolic acids into the alkali and reduce extraction time ${ }^{19}$. Similar extraction conditions were applied to both sorghum and maize as this was a comparative study but it seems that optimal conditions for phenolic extraction vary between the two cereal grains and in particular, for release of diferulic acids in sorghum. 


\section{Effect of microwave-assisted extraction on sorghum and maize phenolic acids.}

Several phenolic acids have been identified and confirmed in sorghum and maize grains. However, in this study, only two phenolic acids were positively identified, which shows that microwaving had an effect on phenolic acid composition. The stability of phenolic acids varies with treatment conditions. With conventional alkaline hydrolysis, $\mathrm{pH}$ is known to affect phenolic acid stability. Among phenolic acids studied, caffeic acid was reported to be $\mathrm{pH}$ sensitive and might undergo irreversible chemical transformation with increasing $\mathrm{pH}^{20}$. Transformations were thought to be due to oxidative degradation or formation of unstable quinone intermediates, which would form diketo derivatives and degradation products ${ }^{20}$. This was attributed to the structure of caffeic acid, which has two phenolic hydroxyl groups in the ortho position capable of forming quinones. Although similar to caffeic acid, ferulic acid has a methylated phenolic hydroxyl group, which is not capable of forming quinones and the methyl group may confer better resonance stability, hence stable to both alkaline and acidic $\mathrm{pH}$ changes. Para coumaric acid is known to confer the greatest stability ${ }^{21}$ and is attributed to the small number of substituents in the aromatic ring ${ }^{22}$. Hence, the identification and quantitation of ferulic acid and $p$-coumaric acid in most cereals could be attributed to their chemical stability. Liazid ${ }^{22}$ studied the stability of phenolic acids including hydroxycinnamic and hydroxybenzoic acid derivatives during MAE. The hydroxycinnamic and hydroxybenzoic acid derivatives were stable up to $150{ }^{\circ} \mathrm{C}$ and their contents were reduced thereafter attributed to their degradation at high temperatures. The extraction temperature of $190{ }^{\circ} \mathrm{C}$ could partly explain why few phenolic acids were identified. As described above, the chemical structure of the phenolic acids plays a role in their stability. Phenolic acids with a few substituent groups in the aromatic ring were found to be more stable during MAE ${ }^{22}$. Moreover, among phenolic acids with the same number of substituents, those that had more methyl groups than hydroxyl groups were less susceptible to 
degradation as confirmed previously ${ }^{21}$. This would be true for ferulic acid and $p$-coumaric acid in the sorghum and maize samples studied. Compared to other phenolic acids, the stability of the phenolic acids was influenced by the methyl group and the small substituent groups in ferulic acid and $p$-coumaric acid, respectively.

Rose and Inglett ${ }^{7}$ used MAE to release esterified ferulic acid from maize bran. The highest amounts of ferulic acid (1.94 and $2.13 \mathrm{~g} / 100 \mathrm{~g})$ were obtained after extracting the samples for 5 and $10 \mathrm{~min}$, respectively at $200{ }^{\circ} \mathrm{C}$, a temperature higher than $190{ }^{\circ} \mathrm{C}$ currently used. However, lower amounts of ferulic acid were obtained under conditions optimal for the release of arabinoxylo-oligosaccharides and would imply an inverse relationship between the release of oligosaccharides and ferulic acid. A combination of MAE and extract purification and pre-concentration using solid phase extraction were found ideal for phenolic acid evaluation ${ }^{23}$. Solid phase extraction reduced interference by pigmented compounds and coelution of substances during HPLC analysis. However, in this study, the purification step was not included, which could have been useful in sorghum to avoid elution of interfering pigmented compounds since the sorghums evaluated were red types.

\section{Relationship between phenolic acids of sorghum and maize with hardness parameters.}

Microwave extracted sorghum bran phenolic acids were not correlated with grain hardness except the significant correlation between kernel size $>4.00 \mathrm{~mm}$ and ferulic acid ( $\mathrm{r}$ $=0.502, \mathrm{p}<0.05)($ Table 5). However, this was not the case with maize as TADD hardness was moderately correlated with $p$-coumaric acid $(r=-0.601)$, ferulic acid $(r=-0.668)$ and diferulic acids $(\mathrm{r}=-0.629)$ at $\mathrm{p}<0.01$ (Table 6). The result is of interest as it shows that diferulic acids influence maize grain hardness and the higher the content, the harder the maize. Also, the results imply that microwave extraction was able to release most of the bound phenolic acids in maize particularly diferulic acids. 
Table 5. Pearson Correlation Coefficients between Sorghum Physical and Hardness Characteristics and Phenolic Acids of Bran Fractions ${ }^{a, b}$

\begin{tabular}{|c|c|c|c|c|c|c|c|c|c|}
\hline & TW & TKW & $\mathrm{KS} 4.00$ & KS 3.35 & KS 3.15 & KS 2.36 & TADD & PCA & FA \\
\hline PCA & 0.0291 & 0.126 & -0.074 & 0.015 & -0.053 & -0.008 & 0.078 & & \\
\hline FA & 0.233 & 0.005 & $0.502 *$ & 0.092 & -0.141 & 0.106 & -0.468 & 0.111 & \\
\hline DFA & -0.058 & -0.305 & 0.128 & -0.235 & 0.194 & 0.384 & -0.453 & 0.471 & $0.733 * *$ \\
\hline
\end{tabular}

${ }^{a}$ TW, Test weight (kg/hl); TKW; Thousand kernel weight (g); KS 4.00, kernel size > $4.00 \mathrm{~mm}$, KS 3.35, kernel size < $4.00>3.35 \mathrm{~mm}$, KS 3.15, kernel size < $3.35>3.15 \mathrm{~mm}$; KS 2.36, kernel size <3.15 >2.36; TADD; \% kernel abraded by a Tangential Abrasive Dehulling Device; PCA, p-coumaric acid; FA, ferulic acid; DFA, diferulic acids.

${ }^{b}$ Significance at $\mathrm{p}<0.05$, denoted by $*$.

Table 6. Pearson Correlation Coefficients between Maize Physical and Hardness Characteristics and Phenolic Acids of Bran and Flour Fractions ${ }^{a, b}$

\begin{tabular}{|c|c|c|c|c|c|c|c|c|c|c|}
\hline & TW & SB & $\mathrm{SC}$ & SCI & TKW & TADD & $\mathrm{KS}$ & NIT & PCA & FA \\
\hline PCA & 0.434 & 0.371 & -0.267 & -0.123 & -0.029 & $-0.601 * *$ & 0.173 & 0.188 & & \\
\hline FA & 0.313 & 0.363 & -0.368 & -0.239 & -0.179 & $-0.668 * *$ & 0.293 & 0.169 & $0.891 * * *$ & \\
\hline DFA & -0.140 & 0.0527 & -0.315 & -0.241 & -0.373 & $-0.629 * *$ & 0.306 & 0.397 & $0.504 *$ & $0.642 * *$ \\
\hline
\end{tabular}

${ }^{a}$ TW, Test weight $(\mathrm{kg} / \mathrm{hl})$; SB, \% breakage susceptibility by Stein breakage tester; TKW; Thousand kernel weight (g); TADD; \% kernel abraded by a Tangential Abrasive Dehulling Device; KS; \% kernel size $\geq 8$ mm; NIT, NIT milling index, PCA, $p$-coumaric; FA, ferulic acid; DFA, diferulic acid.

${ }^{b}$ Significance at $\mathrm{p}<0.01$ and 0.001 denoted by $* *$ and $* * *$, respectively.

The positive correlations between maize ferulic acid and diferulic acids with TADD hardness confirm the influence of these phenolic acids on grain hardness. However, microwaving sorghum at similar conditions with maize does not yield the same results. Since this study is the first to report on microwave extracted sorghum phenolic acids, it is evident 
that mechanisms of phenolic extraction between the two cereals grains are different. More work is required to optimise microwave conditions for extracting bound sorghum phenolic compounds and ascertain the identity of the several unknown compounds, which were unidentified using the external standards and their masses.

\section{Funding Information}

The study was made possible through the financial support provided by the Natural Sciences and Engineering Research Council of Canada (NSERC) Discovery Grant program and the Canada Foundation for Innovation (New Opportunities Fund and Leaders Opportunity Fund).

\section{Acknowledgement}

We acknowledges the technical support received from Yang Qiu of the Department of Food Science, University of Manitoba. The authors are grateful to the Agricultural Research Council for providing sorghum and maize grain samples for research.

\section{REFERENCES}

(1) Adom, K. K.; Liu, R. H. Antioxidant activity of grains. J. Agric. Food Chem. 2002, 50, 6182-6187.

(2) Lam, TB-T.; Iiyama, K.; Stone, B. A. Changes in phenolic acids from internode walls of wheat and phalaris during maturation. Phytochemistry 1992b, 31, 2655-2658.

(3) Munck, L. New milling technologies and products: whole plant utilization by milling and separation of the botanical and chemical components. In: Sorghum and Millets: Chemistry and Technology. D.A.V. Dendy, Ed. American Association of Cereal Chemists: St Paul, MN, 1995: pp 69-124. 
(4) Beejmohun, V.; Fliniaux, O.; Grand, E.; Lamblin, F.; Bensaddek, L.; Christen, P.; Kovensky, J; Fliniaux, M-A.; Mesnard, F. Microwave-assisted extraction of the main phenolic compounds in flaxseed. Phytochem. Anal.. 2007, 18, 275-282.

(5) Provan, G. J; Scobbie , L.; Chesson, A. Determination of phenolic acids in plant cell walls by microwave digestion. J. Sci. Food Agric. 1994, 64, 63-65.

(6) Liu, Z.; Wang, J.; Shen, P.; Wang, C.; Shen, Y. Microwave-assisted extraction and highspeed counter-current chromatography purification of ferulic acid from Radix Angelicae sinensis. Sep. Purif. Technol. 2006, 52, 18-21.

(7) Rose, D.J.; Inglett, G.E. Production of feruloylated arabinoxylooligosaccharides from maize (Zea mays) bran by microwave-assisted autohydrolysis. Food Chem. 2010, 119, 1613-1618.

(8) Qiu, Y.; Liu, Q.; Beta, T. Antioxidant properties of commercial wild rice and analysis of soluble and insoluble phenolic acids. Food Chem. 2010, 121, 140-147.

(9) Lam, TB-T.; Iiyama, K.; Stone, B. A. Cinnamic acid bridges between cell wall polymers in wheat and phalaris intemodes. Phytochemistry. 1992a, 31, 1179-1183.

(10) Hossain, M. B.; Rai, D. K., Brunton, N. P.; Martin-Diana, A. B.; Barry-Ryan, C. J. Characterization of phenolic composition in Lamiaceae spices by LC-ESI-MS/MS. J. Agric. Food Chem. 2010, 58, 10576-10581.

(11) Bily, A. C.; Burt, A. J.; Ramputh, A. L.; Livesey, J.; Regnault-Roger, C., Philogene, B. R.; Arnason, J. T. HPLC-PAD-APCI/MS assay of phenylpropanoids in cereals. Phytochem. Anal.. 2004, 15, 9-15.

(12) Callipo, L.; Cavaliere, C.; Fuscoletti, V.; Gubbiotti, R.; Samperi, R.; Lagana, A. Phenilpropanoate identification in young wheat plants by liquid chromatography/tandem mass spectrometry: monomeric and dimeric compounds. J. Mass Spectrom. 2010, 45, 1026-1040.

(13) Parejo, I.; Jauregui, O.; Sanchez-Rabaneda, F.; Viladomat, F.; Bastida, J.; Codina, C. Separation and characterization of phenolic compounds in fennel (Foeniculum vulgare) using liquid chromatography-negative electrospray ionization tandem spectrometry. J. Agric. Food Chem. 2004, 52, 3679-3687. 
(14) Andreasen, M. F.; Christensen, L. P.; Meyer, A. S.; Hansen, A. (2000). Ferulic acid dehydrodimers in rye (Secale cereale L.). J. Cereal Sci. 2000, 31, 303-307.

(15) Waldron, K. W.; Parr, A. J.; Ng, A.; Ralph, J. Cell wall esterified phenolic dimmers: Identification and quantification by reverse phases high performance liquid chromatography and diode array detection. Phytochem. Anal.. 1996, 7, 305-312.

(16) Dobberstein, D.; Bunzel, M. Separation and detection of cell wall-bound ferulic acid dehydrodimers and dehydrotrimers in cereals and other plant materials by reversed phase highperformance liquid chromatography with ultraviolet detection. J. Agric. Food Chem. 2010, 58, 89278935.

(17) Chandrashekar, A.; Mazhar, H. The biochemical basis and implications of grain strength in sorghum and maize. J. Cereal Sci. 1999, 30, 193-207.

(18) Parker, M. L.; Ng, A.; Waldron, K. W. The phenolic acid and polysaccharide composition of cell walls of bran layers of mature wheat (Triticum aestivum L. cv. Avalon) grains. J. Sci. Food Agric. 2005, 85, 2539-2547.

(19) Cacace, J. E.; Mazza, G. Mass transfer process during extraction of phenolic compounds from milled berries. J. Food Eng. 2003, 59, 379-389.

(20) Friedman, M.; Jurgens, H. S. Effect of pH on the stability of plant phenolic compounds. J. Agric. Food Chem. 2000, 48, 2101-2110.

(21) Krygier, K.; Sosulski, F.; Hogge, L. Free, esterified and insoluble-bound phenolic acids. 1. Extraction and purification procedure. J. Agric. Food Chem. 1982, 30, 330-334.

(22) Liazid, A.; Palma. M.; Jamal Brigui, J.; Barroso, C. G. Investigation on phenolic compounds stability during microwave-assisted extraction. J. Chromatogr. A. 2007, 1140, 29-34.

(23) Sterbova, D.; Matejıcek, D.; Vlcek, J.; Kuban, V. Combined microwave-assisted isolation and solid-phase purification procedures prior to the chromatographic determination of phenolic compounds in plant materials. Anal. Chim. Acta, 2004, 513, 435-444 